\title{
Energy Efficiency Drivers in South Africa: 1965-2014
}

\author{
Goodness C. Aye ${ }^{*}$, Rangan Gupta ${ }^{* * *}$ and Peter Wanke ${ }^{* * *}$
}

\begin{abstract}
This paper presents an assessment of energy performance in South Africa from 1965-2014 using the Technique for Order of Preference by Similarity to Ideal Solution (TOPSIS). In this research, TOPSIS is used first in a two-stage approach to assess how energy in South Africa has performed using the most frequent indicators adopted by the literature. Afterwards, in the second stage, neural networks are combined with TOPSIS results as part of an attempt to produce a model for energy performance with good predictive ability. The results reveal different impacts of contextual variables such as the rise of China in foreign trade, the Apartheid Regime, and oil shocks on energy performance in South Africa.
\end{abstract}

Keywords: energy; performance, South Africa; TOPSIS; two-stage; neural networks.

\section{Introduction}

This paper analyzes the energy performance in South Africa from 1965-2014. The motivations for this research are twofold. First, this paper is innovative in relation to energy performance because it evaluates its evolution in South Africa from a historical perspective. In this research, this evolutionary analysis is undertaken for the South African energy sector by adopting TOPSIS and neural networks in a two-stage approach. Second, the present

\footnotetext{
${ }^{*}$ Corresponding author. Department of Economics, University of Pretoria, Pretoria, 0002, South Africa. Email: goodness.aye@gmail.com.

** Department of Economics, University of Pretoria, Pretoria, 0002, South Africa. Email: rangan.gupta@up.ac.za

${ }_{* * * *}$ COPPEAD Graduate Business School, Federal University of Rio de Janeiro, Rua Paschoal Lemme, 355. 21949-900 Rio de Janeiro. Email: peter@ coppead.ufrj.br.
} 
analysis enables a ranking of the relative performance for each year within the range comprised between 1965 and 2014 with a predictive focus.

Performance is a broader concept that can be assessed by means of technical or cost efficiency. Efficiency is another stream of performance studies, with assumptions on the productive frontier or data envelop. Performance is usually employed at the public sector where there may be difficulties in comparing with peers and for quantifying monetary values for inputs and outputs (Mihaiu et al., 2010). Hence, productive efficiency is not the only way for accessing performance (Talley, 2007). Performance can also be assessed with MultiCriteria Decision Making (MCDM) methods like Technique for Order Preference by Similarity to Ideal Solution (TOPSIS) (Behzadian et al., 2012). Efficiency is saved to DEA and stochastic frontier analysis (SFA), that is, either parametric or nonparametric methods that compute performance based on productive frontiers that envelopes a data set. On the other hand, multicriteria methods develop cardinal or scale metrics on positive and negative ideal solutions or combinations that are obtained through linear combinations of the raw data. TOPSIS measures performance in qualitative terms while DEA measures it quantitatively (Zeydan and Çolpan, 2009). The distance or performance in traditional TOPSIS is cardinal, consisting of a second power metric, that is, an Euclidean n-space with the Euclidean distance, which are complete metric spaces (Olson, 2004). In other words, TOPSIS computes cardinal distances (scores) from ideal positive solutions while simultaneously presents an ordinal ranking of them (Behzadian et al., 2012). Therefore, we compute the performance of South African energy in the light of a possible ideal solution computed by the data.

TOPSIS as a performance measure has been applied in several areas including human resources management (Kelemenis, et al., 2011; Boran, et al., 2011), supply chain management and logistics (Chen et al., 2006; Kahraman et al. 2009; Zeydan and Çolpan, 2009), business and marketing management (Kahraman et al. 2009), financial management (Bulgurcu, 2012), engineering and manufacturing systems (Rao and Baral, 2011), water resources and environment (Gomez-Lopez, et al., 2009; Afshar et al., 2011) and energy management (Kaya and Kahraman, 2011; Yan, et al. 2011), amongst others. In energy performance for instance, Kaya and Kahraman (2011) proposed a modified fuzzy TOPSIS methodology to select the best energy technology according to technical, economic, 
environmental and social criteria. Yan, et al. (2011) applied a new GRD-TOPSIS method to investigate the performance of coal enterprise energy conservation and pollutant emission reduction. Chamodrakas and Martakos (2011) presents a utility-based fuzzy TOPSIS method that takes into account user preferences, network conditions, QoS and energy consumption requirements in order to select energy efficient network in heterogeneous wireless networks. Afsordegan et al. (2016) evaluated seven energy alternatives under nine criteria according to the opinion of three environmental and energy experts. The weights of the criteria are determined by fuzzy AHP, and the alternatives are ranked using qualitative TOPSIS.

As far as South Africa is concerned, most of the studies on the performance of energy are basically descriptive or exploratory in nature (see Gouws et al. (2012), Winkler and van Es (2007), and Fawkes (2005) for example). Perhaps the only quantitative studies are Kohler (2013), Inglesi-Lotz and Blignaut (2011), Inglesi-Lotz and Pouris (2012), and Song et al. (2013). These quantitative studies focused on analyzing energy performance via the route of energy efficiency that was computed based on the IEA energy intensity measure.

Based on the literature review, our paper contributes in the following ways: First, we consider energy performance in light of different contextual variables such as the rise of China in foreign trade, the Apartheid regime, and the oil shocks. Second, we use a much longer and recent sample (1965-2014) that enables us to track the trend of energy performance over time. Finally, our study also employs a different methodology for energy assessment in the energy literature (TOPSIS and neural networks) following a trend in other research areas (e.g. Barros and Wanke, 2015) that enables us to not only examine the energy performance, but also analyze contextual factors that may influence energy performance. We are not aware of any study that has used MCDM technique and specifically TOPSIS combined with neural networks to assess energy performance at the country level in such long time span as in this study.

The paper is structured as follows: after this introduction, the contextual setting is presented including a description of the energy sector in South Africa in section 2. Section 3 presents the methodology section on TOPSIS, neural networks, and the global separability between contextual variables and performance scores in a two-stage approach. Section 4 
presents the analysis of the results followed by the respective discussion. Policy implications for South Africa decision-makers are discussed in the conclusions under section 5.

\section{Contextual Setting: Energy Performance in South Africa}

Energy is a key input in a number of production and related processes. Its usefulness is evident in the industrial sector for transportation, street lighting, residential, commercial, and government buildings, among other sectors. Due to rising population and the pursuit of economic growth, the demand for energy has been increasing in recent times, thus putting an upward pressure on energy prices. The world population grew by 4 times, economic output by 22 times, and fossil fuel consumption by 14 times during the 20th century (UNEP, 2011). The global primary energy demand is projected to increase on average by $1.3 \%$ per year from 2009 to 2035, while the average IEA crude oil import prices will approach USD 120 per barrel (in year-2010 dollars) in 2035 based on the WEO-2011 new policies scenario (OECD, 2011). Improving energy performance in these countries is more important than ever given that energy demand in emerging economies is projected to grow significantly over the next decades. The 2013 World Energy Outlook (WEO) predicts that the center of gravity of energy

demand will switch decisively to emerging economies, driving global energy use one-third higher under the New Policies Scenario. This scenario forecasts that emerging economies will account for more than $90 \%$ of global net energy demand growth by 2035 (IEA 2013a; IEA, 2015).

South Africa, an emerging economy, and our case study, is reported to be one of the highest in energy intensity (primary energy use per unit of GDP) in the world, reaching 2.74 tonnes of oil equivalent (toe) per capita in 2010, which is higher than the world average of 1.87 (IEA 2013b). Both production and use of energy have grown steadily since 2001. Its Total Primary Energy Supply (TPES) and Total Final Consumption (TFC) reached 141 million tonnes of oil equivalent (Mtoe) and 71 Mtoe respectively in 2011, which is approximately $20 \%$ of the African continent's total energy supply (IEA, 2013b). South Africa's energy intensity in recent years appears to have been declining according to IEA (2012, 2013b), but this compares unfavorably with larger average reductions for both OECD and non-OECD countries. Kohler (2013) noted that the high energy intensity of South Africa 
partly reflects the natural resource endowments of coal and other mineral resources in particular, but it is also a function of the domestic underpricing of coal and electricity by the authorities for a long period of time. The low cost of power with inexpensive and subsidized domestic fossil energy resources allows large industrial and public sector customers to pay prices as low as South African Rand (ZAR) 0.18 per kilowatt hour (kWh) (USD 0.024 per kWh) (The International Finance Corporation and African Development Bank (IFC and AfDB, 2010) cited in IEA (2013b).

The increasing demand for energy calls for concern and policy action because it not only impairs energy security, but also leads to increasing environmental damage due to greenhouse gas emissions, particularly $\mathrm{CO}_{2}$ emissions from fossil fuel combustion. South Africa is ranked as the 12th largest emitter of $\mathrm{CO}_{2}$ emissions in the world and is responsible for about $1.6 \%$ of global emissions and almost $50 \%$ of the $\mathrm{CO}_{2}$ emissions in Africa (International Emissions Trading Association, IETA, 2014). IETA (2014) also noted that carbon dioxide accounts for approximately $80 \%$ of total greenhouse gas emissions in South Africa. The entire world depends mostly on coal, the most carbon-intensive fossil fuel, for the generation of electricity and heat, and countries such as Australia, China, India, Poland, and South Africa produce over two-thirds of their electricity and heat through the combustion of coal (IEA, 2014a). About 94\% of South Africa's electricity is produced from coal (IEA, 2013b).

Although the South African government realized the need for greater generation and distribution capacity, which led its state-owned utility company, Eskom, to remobilize longdecommissioned power stations, such measures were insufficient to prevent rolling blackouts. Therefore, Eskom had to return to load shedding, yet it still faces suboptimal reserve margins. A continuing power shortage remains one of the greatest motivations for energy improvement in South Africa. Hence, as energy security crisis looms, the South African government has put in place energy improvement policies and strategies to deal effectively with potential electricity capacity shortages, environmental concerns, and the rising price of energy sources. The latest overarching energy improvement target for South Africa comes from the 2005 National Energy Efficiency Strategy last reviewed in 2012, which emphasizes solving the energy security problem through Energy Efficiency (EE) and 
Demand Side Management (DSM). It maintains a target for energy efficiency improvement at $12 \%$ by 2015 for the country as a whole (below a business-as-usual projection from 2000 levels) measured as a 12\% reduction in energy intensity (actual energy usage per Rand of GDP) (IEA, 2013b). According to the Department of Energy (DOE, 2014), this target was further disaggregated into sectoral targets as follows: industrial and mining (15\%), commercial and public buildings (15\%), residential (10\%), and transport (9\%). Energy improvements is expected to be achieved largely via enabling instruments and interventions such as economic and legislative means, efficiency labels and performance standards, energy management activities, energy audits, as well as the promotion of efficient practices, among others (Department of Minerals and Energy, 2005). Currently, the country implements a 12L tax incentive (45 cents per kilowatt hour) for businesses to reduce electricity demand and improve energy performance. This was formerly launched on December 4, 2013.

\section{Methodology}

This section presents the major methodological steps adopted in this research. After presenting the data collected in terms of ranking of criteria and contextual variables, the twostage approach is explained in detailed. Section 4.2 is devoted to discussing the application of the TOPSIS method to this research in light of the major differences with respect to DEA models and section 4.3 depicts the neural network analysis adopted here and explains how the results were validated and interpreted by means of sensitivity analysis.

\subsection{The data}

The data on the South African energy consumption and related variables covers from 1965 to 2014 and were obtained from several sources. More precisely, data on employment and labor force were obtained from the International Monetary Fund's International Financial Statistics, for $\mathrm{CO}_{2}$ emissions and energy consumption from BP's 2015 statistical review of world energy, and for the GDP and the capital stock from the South African Reserve Bank. The variables collected are the observed inputs and outputs usually found in the literature review and based on data availability. The inputs are labor force (number of employees in thousands), energy consumption (in million tonnes of oil equivalent - Mtoe), and the 
productive capital stock (in 2010 constant South African Rand - million ZAR). Due to its undesirable nature, $\mathrm{CO}_{2}$ emissions (in metric tons of Carbon) were also treated as an inputor as a performance criterion - that should be minimized. In other words, the $\mathrm{CO}_{2}$ variable is assigned a negative sign for the weight in TOPSIS and hence it entered as a negative criteria, similarly to DEA models where it enter as an input. On the other hand, Gross Domestic Product (GDP, in 2010 constant South African Rand - million ZAR) was the single output considered. Their descriptive statistics are presented in Table 1.

Furthermore, a number of contextual variables were collected to explain differences in the performance levels that are also presented in Table 1 and are related to major demographics/economics of South Africa during these years. Dummies were created to access whether or not the country was under the Apartheid regime, whether or not the country was under the effect of both oil shocks of the 70's, or whether or not the country was experiencing the impacts of the rising of the Chinese foreign trade and its impacts all over the world on the productive chains at a given moment of time. Besides a linear and a squared trend component, additional ratios were computed such as the capital-labor ratio (KL ratio) that was calculated by dividing the stock of productive capital by the labor force in a given year, and the $\mathrm{CO}_{2}$ /Energy ratio obtained by dividing the $\mathrm{CO}_{2}$ emissions by the amount of energy consumed in a given year. At last, the seasonally adjusted manufacturing employment index was also considered.

Table 1: Descriptive statistics for the TOPSIS criteria and the contextual variables

\begin{tabular}{|c|c|c|c|c|c|}
\hline \multicolumn{2}{|c|}{ Variables } & Min & Max & Mean & SD \\
\hline \multirow{5}{*}{ Inputs and Outputs } & Labor Force & 4608540.952 & 15146500.000 & 9098000.889 & 3045467.191 \\
\hline & $\begin{array}{l}\text { Capital Stock in ZAR } \\
\text { Millions }\end{array}$ & 2183382.000 & 7456244.000 & 4693846.340 & 1373906.335 \\
\hline & $\mathrm{CO} 2$ emissions & 114.864 & 457.474 & $\begin{array}{r}294.397 \\
\end{array}$ & $\begin{array}{l}109.991 \\
\end{array}$ \\
\hline & Energy Consumption & 30.263 & 126.691 & 80.508 & 31.053 \\
\hline & GDP & 784781.000 & 3008576.000 & 1719701.220 & 610796.343 \\
\hline \multirow{5}{*}{$\begin{array}{l}\text { Contextual and } \\
\text { Business-related } \\
\text { characteristics }\end{array}$} & KL Ratio & 0.438 & 0.652 & 0.523 & 0.070 \\
\hline & $\mathrm{CO}_{2}$ /Energy Ratio & 3.569 & 3.796 & 3.678 & 0.062 \\
\hline & Employment Index & 74.444 & 130.107 & 110.778 & 14.161 \\
\hline & Apartheid Regime & 0.000 & 1.000 & 0.600 & 0.490 \\
\hline & Oil Shock & 0.000 & 1.000 & 0.160 & 0.367 \\
\hline
\end{tabular}




\begin{tabular}{|l|l|r|r|r|r|}
\hline & China Emergence & 0.000 & 1.000 & 0.400 & 0.490 \\
\cline { 2 - 5 } & Trend & 1.000 & 50.000 & 25.500 & 14.431 \\
\cline { 2 - 6 } & Trend $^{2}$ & 1.000 & 2500.000 & 858.500 & 759.152 \\
\hline
\end{tabular}

\subsection{TOPSIS}

The design and application of Multi-Criteria Decision Making (MCDM) methods have been a prolific research field in business analytics and engineering. As a matter of fact, over the course of the last three decades, a variety of different MCDM have been developed and empirically employed in the field of research. This list includes the AHP (Saaty, 1980; Ramanathan, 2013), Promethee (Brans and Vincke, 1985; Corrente et al., 2013), Electre (Hatami-Marbini and Tavana, 2011; Corrente et al., 2013), Dematel (Tsay et al., 2009), Vikor (Opricovic, 1998; Opricovic and Tzeng, 2007), and Uta (Siskos et al., 2014).

The TOPSIS method (Technique for Order of Preference by Similarity to Ideal Solution), which was first developed by Hwang and Yoon (1981), is a widely accepted MCDM technique (Behzadian et al., 2012). According to Hwang and Yoon (2012), TOPSIS belongs to the group of methods devoted to the linear ordering of multidimensional objects. Broadly speaking, the ordering of objects from the best to the worst, considering an assumed synthetic measure that is not subject to a direct measurement, belongs to the task of linear ordering (Jefmański \& Dudek, 2015). This distinctive feature of TOPSIS is a particular way to evaluate a synthetic criterion's values taking into account the distance of an evaluated object to the positive-ideal solution as well as to a negative-ideal solution (Tavana et al., 2013). Wang et al. (2014), Barros and Wanke (2015), and Wanke, et al. (2015a, 2015b) are examples of applications of the TOPSIS method in performance measurement problems in which the positive-ideal solution represents $100 \%$ performance and the negative-ideal solution $0 \%$ performance. Its basic principle, it assumes that any chosen alternative should simultaneously present the shortest distance from the positive-ideal solution and the farthest distance from the negative-ideal solution (Hwang and Yoon, 1981). Putting it in other words, the TOPSIS method is based on the concept that the positive ideal solution has the best level for all attributes considered, while the negative ideal is the one with the worst values attributed. Besides, it is possible to affirm that the positive-ideal solution is the one that maximizes benefits and also minimizes total costs. On the contrary, the negative-ideal 
solution is the one that minimizes benefits while maximizing costs (Lai et al., 1994; Wu et al., 2010; Ertugrul and Karakasoglu, 2009).

TOPSIS is one of the MCDM approaches used where the weighting criteria for the choice of the most adequate solution is exogenously defined (Wang et al., 2014; BilbaoTerol, et al., 2014; Feng and Wang, 2001; Pirdavani et al., 2010; Chen et al., 2014; Hassan et al., 2013; Barros and Wanke, 2015). Due to this weighting flexibility, TOPSIS presents the advantages of geometric aggregation methods such as those presented in Zhou et al. (2006) and Zhou and Ang (2009), although it does not suffer from their major drawback, compensability, where poor performance in some criteria can be compensated by sufficiently high values in other criteria (Munda and Nardo, 2003). Besides, despite its general resemblance to DEA objectives where outputs may be maximized and/or inputs minimized in non-radial/radial models, the determination of the weights of the relative importance of each criteria, namely benefits and costs or simply outputs and inputs, respectively, is a milestone step in TOPSIS methodology, whereas, in the case of DEA, these weights are calculated within the ambit of the model (Behzadian et al., 2012). Moreover, DEA may suffer from a lack of discriminatory power due to the fact that many observations are located in the frontier of efficiency, which differs from TOPSIS and other MCDM models where discriminatory power is high. However, unlike SFA, both DEA and TOPSIS do not impose any functional form on the data, neither do they make any distributional assumption for the scores calculated. This issue is of utmost importance when conducting the robustness analysis on the global separability of criteria and contextual variables in the sense that conditional distributions on performance scores are assessed empirically rather than imposing a functional form between them as done in SFA models. Another difference from DEA models is the fact that, while DEA optimizes the distance from each observation to the convex-efficient production frontier by finding a proper set of weights for inputs and outputs (Chen, 2002), TOPSIS purely employs analytical methods based on applying Euclidean distance functions on normalized vectors of positive (outputs) and negative (inputs) criteria, given that the weights have already been defined previously by the decision-maker (Barros and Wanke, 2015). Since TOPSIS is comparatively simpler when compared to DEA models, there are virtually no computational constraints with respect to the number of observations and criteria that can be assessed. 
The TOPSIS technique is built upon an evaluation matrix consisting of $m$ alternatives and $n$ criteria with the intersection of each alternative and criteria given as $x_{i j}$. Therefore, one obtains a matrix $\left(x_{i j}\right)_{m x n}$. This matrix $\left(x_{i j}\right)_{m x n}$ should be firstly normalized from a regulated matrix $R^{*}=\left(r_{i j}\right)$ as demonstrated in Eq. (1).

$$
r_{i j}=x_{i j} / \sqrt{\sum_{i=1}^{m} x_{i j}^{2}}, i=1,2, \ldots m \text { and } j=1,2, \ldots, n
$$

After normalization the weighted normalized decision matrix for performance assessment should be calculated, observing Eq. (2):

$W=\left(w_{i j}\right)_{m x n}=\left(w_{j} r_{i j}\right)_{m x n}$

where $w_{j}$ is the weight given to the criteria $j$ and $\sum_{j=1}^{n} w_{j}=1$.

With respect to defining the weighing criteria, several different methods can be found in literature. Because of this, there is not a single methodological procedure to be followed (Madeira Júnior et al., 2012). Hemmati et al. (2013) for instance used the Entropy technique. Seçme et al. (2009) and Shaverdi et al. (2011) in contrast used fuzzy AHP for determining the weights of main and sub-criteria. In our study, the five attributes or criteria presented in Table 1 have been initially given the same weight with a fair consideration since the literature review provides no clear indication about which criteria are preferable to the detriment of the others for assessing energy performance. However, a robustness analysis on the weighting criteria, based on a linear programming model, is further discussed in Section 3.4. The underlying idea is to assess how changes in weighting may affect the linear ordering of South African energy performance over the course of the years.

Anyway, in a broader sense, once the weighting criteria is defined, the worst alternative (the negative ideal assessment unit) $A_{a}$ and the best alternative (the positive ideal assessment unit) $A_{b}$ should be defined using Equations (3) and (4):

$$
\begin{aligned}
& A_{a}=\left\{\left\langle\min \left(w_{i j} \mid i=1,2, \ldots, m\right) \mid j \in J_{+}\right\rangle,\left\langle\max \left(w_{i j} \mid i=1,2, \ldots, m\right) \mid j \in J_{-}\right\rangle\right\}=\left\{\alpha_{a j} \mid j=1,2, \ldots, n\right\} \\
& A_{b}=\left\{\left\langle\max \left(w_{i j}|i=1,2, \ldots, m| j \in J_{+}\right\rangle,\left\langle\min \left(w_{i j} \mid i=1,2, \ldots, m\right) \mid j \in J_{-}\right\rangle\right\}=\left\{\alpha_{b j} \mid j=1,2, \ldots, n\right\}\right.
\end{aligned}
$$


where $J_{+}=\{j \mid j \in$ positive $\}$ and $J_{-}=\{j \mid j \in$ negative $\}$, which are a set of positive (benefit) and negative (cost) attributes, respectively.

Given the best and the worst alternatives, the distance $d_{i a}$ between the target alternative $i$ and the worst condition $A_{a}$ should be calculated using Eq. (5):

$$
\left.d_{i a}=\sqrt{\sum_{j=1}^{n}\left(w_{i j}\right.}-\alpha_{a j}\right)^{2}, i=1,2, \ldots, m
$$

and the distance $d_{i b}$ between the alternative $i$ and the best condition $A_{b}$ by observing Eq. (6).

$$
\left.d_{i b}=\sqrt{\sum_{j=1}^{n}\left(w_{i j}\right.}-\alpha_{b j}\right)^{2}, i=1,2, \ldots, m
$$

where $d_{i a}$ and $d_{i b}$ are the Euclidean distance from the target alternative $i$ to the worst and best conditions, respectively.

Then, the similarity of alternative $i$ to the worst condition (the inefficient best conditions) should be computed, respectively, as:

$S_{i}=d_{i a} /\left(d_{i a}+d_{i b}\right)$

where $0 \leq S_{i} \leq 1, i=1,2, \ldots, m$.

$S_{i}=0$, if and only if the alternative solution has the worst condition.

$S_{i}=1$, if and only if the alternative solution has the best condition.

According to Jahanshahloo et al. (2009), $S_{i}$ represents the performance scores for each alternative, which is each year of the South African sample, determined by the decision making criteria.

Finally, the alternatives should be ranked according to $S_{i}$ where a value higher than $S_{i}$ indicates a better solution with respect to higher performance levels within this 50 -year time span of energy consumption in South Africa, allowing a subsequent assessment of the impact of contextual variables.

\subsection{On the use of artificial neural networks for performance prediction}


In this research, the choice of the predictive modeling technique observes the fact that new developments in statistical software technologies can be used to support systematic theory testing and development (Tsui et al., 2000; Chen and Cheng, 2013; Osei-Bryson and Ngwenyama, 2014). Predictive modeling is the process by which a technique is created or chosen to try to best predict the probability of an outcome (Geisser, 1993). More specifically, established management science techniques such as TOPSIS can be used in combination with several predictive modeling techniques to more effectively explore research questions on performance measurement (Chen, 2007). In this paper, the ideas of Kuhn and Johnson (2013) are followed on how to manage the trade-off between interpretability and accuracy. Thus, if a model is created to make some prediction, it should not be constrained by the requirement of interpretability and/or significance of statistical results. Moreover, as long as the model can be appropriately validated, it should not matter whether it is a black box or a simple, interpretable model.

Therefore, rather than predicting performance itself, a more difficult problem is obtaining trustworthy estimates of performance for the artificial neural network employed. The apparent error rate can produce extremely optimistic performance estimates (Kuhn and Johnson, 2013). Resampling is the underlying idea for estimating the variability of a predictive technique fit (James et al., 2013). There are several resampling procedures, but they all operate quite similarly: a subset of samples is used to fit a model and the remaining samples are used to re-estimate the model's accuracy (Kuhn and Johnson, 2013).

Cross-validation and bootstrap are two of the most commonly used resampling tools for the practical application of many statistical learning techniques (James et al., 2013). For example, cross-validation can be used to estimate the test error associated with the artificial neural network in order to evaluate its accuracy. There is a number of resampling procedures frequently used in cross-validation: Bootstrap, k-Fold, Repeated k-Fold, and Leave One Out. A comprehensive review of these techniques can be found in Kuhn and Johnson (2013) and James et al. (2013).

Importantly, with respect to the context of energy performance, most of the studies previously presented aimed to explain the factors affecting performance (using bootstrapped truncated and Tobit regressions, for example), yet no predictive analysis has been done in the 
sense of pushing up the predictive limits of the model. Whereas the prediction of energy performance is extremely important, poor performance may lead to an eventual failure in achieving the goals of the Kyoto's protocol. Thus, conceiving a predictive model for energy performance would be useful in avoiding or at least limiting such undesirable consequences related to $\mathrm{CO}_{2}$ emissions. Therefore, this study also proposes the use of contextual variables to predict energy performance. More specifically, neural networks are trained to assess how contextual variables could be used as predictors of energy performance levels in South Africa. Emerging literature exists that combines MCDM results (TOPSIS included) from the first stage with variations on the neural network architecture from the second stage for predictive modelling in several areas of knowledge (Azadeh et al., 2014).

Artificial Neural Networks (ANNs) are powerful nonlinear regression techniques inspired by theories about how the brain works (Bishop, 1995; Ripley, 1995; Titterington, 2010). They are formed by a set of computing units (the neurons) linked to each other (Claveria and Torra, 2014). Each neuron executes two consecutive calculations: a linear combination of its inputs followed by a nonlinear computation of the result to obtain the output value that is then fed to other neurons in the network (Torgo, 2011).

Like partial least squares, the outcome is modelled by an intermediary set of unobserved variables called hidden layers (Kuhn and Johnson, 2013). These hidden layers are located in between the first layer, which contains the input neurons, and the final layer, which contains the predictions of the neural network for any case presented at its inputs neurons (Torgo, 2011; Chen et al., 2015). Therefore, one needs to decide on the number of hidden layers and the number of inputs in the various layers, as well as the weights that connect the inputs and the outputs of these layers (Ledolter, 2013; Feng and Zhang, 2014).

ANNs are known to be sensitive to different scales of the variables used in a prediction problem. In this context, it makes sense to transform the data before introducing them to the network, usually by normalizing (Torgo, 2011). Additionally, like their regression counterparts, neural networks for classification have a significant potential for over-fitting that should be handled by cross-validation (Kuhn and Johnson, 2013). 


\subsection{Robust TOPSIS weighting: Applying the Ng model}

With respect to the definition of the weighing criteria, several different methods can be found in literature, thus, there is not a single methodological procedure to be followed (Madeira Junior, Cardoso Junior, Belderrain, Correia, \& Schwanz, 2012). In our study, the four inputs and the single output presented in Table 1 were initially given the same weight, since the literature review provides no clear indication as to which criteria should be prioritized for ranking years in the South African energy context.

Importantly, this study conducts a robustness analysis based on the guidelines provided in Wanke et al. $(2015,2016)$. The underlying idea is to assess how different weighting criteria would impact the computation of TOPSIS performance scores, compared to those derived from the initial ones, where the equal weighting assumption was considered. The steps taken in generating different weightings are further detailed in the next paragraphs and presented in the discussion section. Readers should note, however, that despite the weighting criteria adopted, the contextual variables are further used as performance predictors in the Tobit regression and in the Neural Network analyses, for the base case where all weights are assumed to be equal.

The Ng weighting model applied to this research assumes that there are $I$ year observations, and that they should be ranked in terms of $J$ inputs and outputs. Further, let the performance of $i$-th year observation in terms of each of the $j$-th input and output be denoted as $y_{i j}$. The purpose is to aggregate multiple performance scores of a year observation with respect to different input and outputs into a single score for the subsequent ranking. In the $\mathrm{Ng}$-model, the author first transforms all measures to a baseline for purposes of comparison. Using the transformation:

$$
\frac{y_{i j}-\min \left\{y_{i j}\right\}}{\max \left\{y_{i j}\right\}-\min \left\{y_{i j}\right\}}
$$

The Ng-model converts all measurement in a $0-1$ scale for all items. To facilitate the year ranking under multiple input/output, $\mathrm{Ng}$ defines a nonnegative weight $w_{i j}$ which is the weight of contribution of performance of the $i-$ th year under the $j$-th criteria (input or 
output) to the score of the item. The criteria are assumed to be ranked in a descending order, such that $w_{i 1} \geq w_{i 2} \geq \ldots \geq w_{i J}$ for all year i. The $\mathrm{Ng}$ (2007) model for computation purposes is given as follows:

$$
\begin{array}{ll}
\max & S_{i}=\sum_{j=1}^{J} y_{i j} w_{i j} \\
\text { s.t. } & \sum_{j=1}^{J} w_{i j}=1 \\
& w_{i 1} \geq w_{i 2} \geq \ldots \geq w_{i J} \\
& w_{i j} \geq 0, \quad i=1, \ldots, I \& j=1, \ldots, J
\end{array}
$$

\section{Results and Discussion}

The performance levels calculated for the energy consumption in South Africa from 1965 to 2014 using the TOPSIS approach and considering different grouping criteria are given in Fig. 1 and the complete ranking is presented in the Appendix. One can easily note that energy performance in South Africa is systematically decreasing over the course of this 50-year time span. Generally speaking, energy performance in South Africa might be decreasing due to a proportionally larger amount of energy consumption, $\mathrm{CO}_{2}$ emissions, labor force, and capital stock with respect to the GDP achieved each year, or due to a combination of these variables to some extent. Additionally, Fig. 2 reveals substantial differences when performance are grouped by each dummy contextual variable related to the Apartheid regime, the rise of China's foreign trade, and the oil shock. Energy performance in South Africa were clearly better during the Apartheid, prior to the rise of China as a commercial and industrial superpower, in parallel to the oil shocks in the 70s that stimulated the use of alternative fuel sources and various programs for energy conservation and saving. As a matter of fact, the decline of the South African energy performance coincided with the change of its economy towards low-value added services, which is detrimental to industrial, capital intensive activities that are more pollutant, due to an excess of workforce liberated from the end of the Apartheid regime and the relocation of global 
industrial activity to China (cf. Fig. 3) (Statistics South Africa, 2015). ${ }^{1}$ Furthermore, the participation of the industrial activity in South Africa's GDP declined from an average 22$23 \%$ in the 60 s, 70 s, and 80 s to less than $15 \%$ in more recent years.

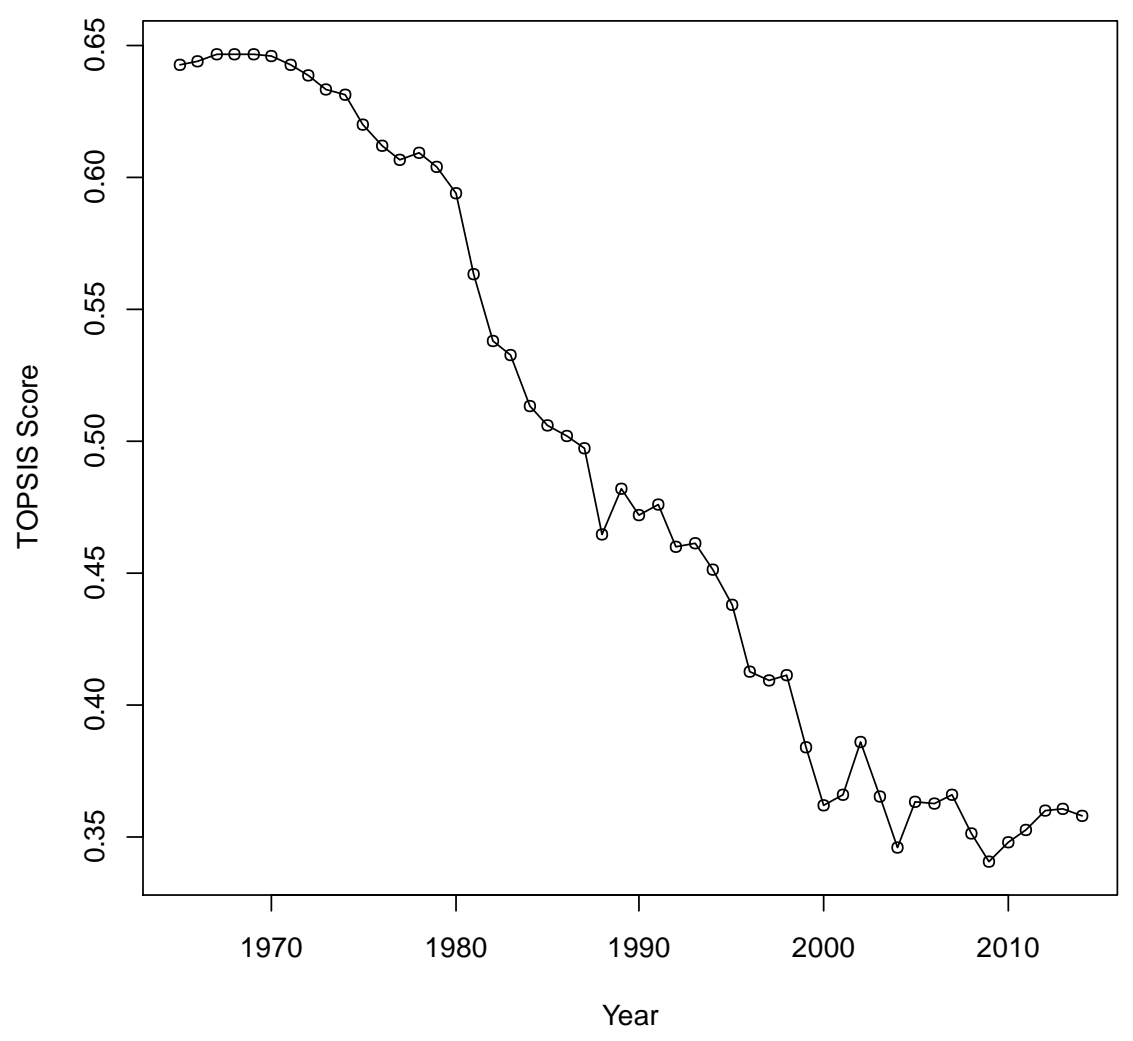

Fig. 1. Energy performance in South Africa from 1965-2014.

${ }^{1}$ http://www.statssa.gov.za/?page id=735\&id=1. 

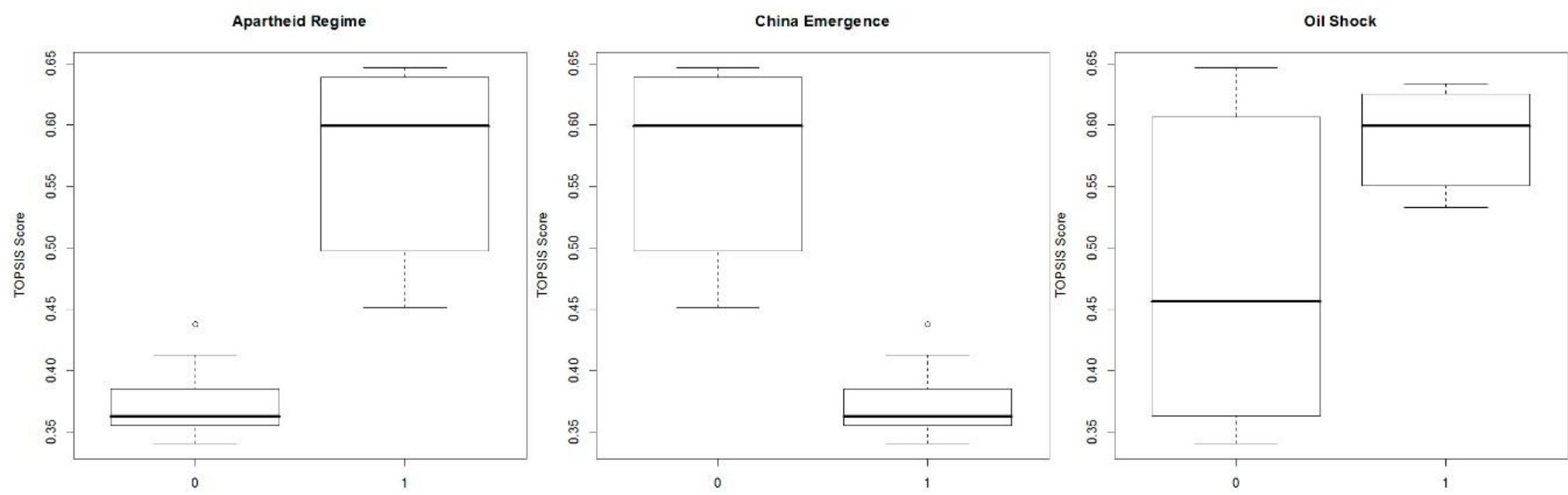

Fig. 2. Distribution of performance scores per dummy contextual variables $(1=$ yes $/ 0=$ no). 

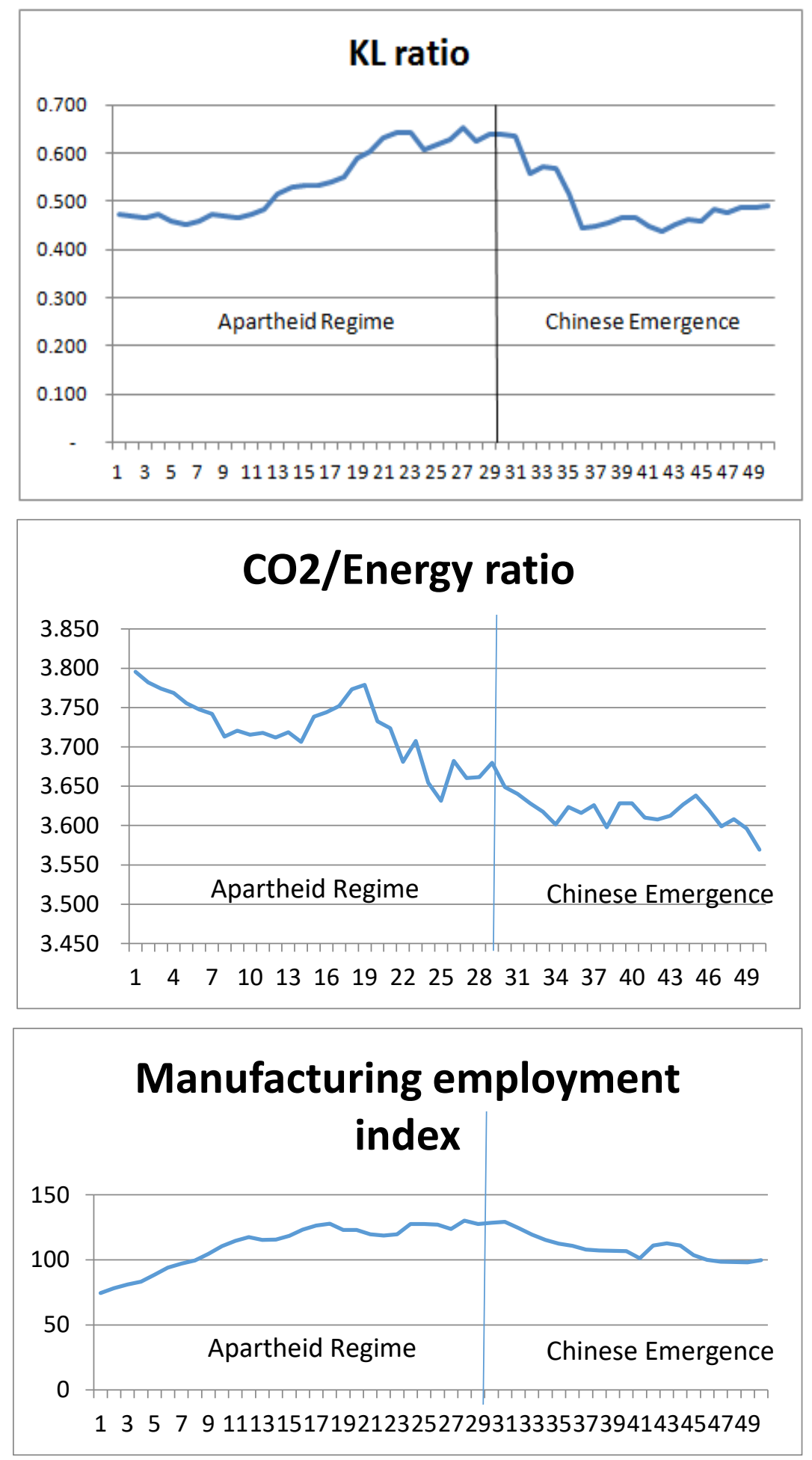

Fig 3. Evolution of contextual variables over time (x-axis indicates the time span; 1 corresponds to 1964 and 50 to 2014) 
Putting this scenario into perspective, a robustness analysis was then performed in order to compare the TOPSIS scores with those computed from the traditional BCC (Banker et al., 1984) and CCR (Charnes et al., 1978) models (cf. Fig. 4). It should be mentioned that the undesirable output of $\mathrm{CO}_{2}$ emissions was considered as an input that should be minimized, a common practice in DEA models (Apergis et al., 2015), which was also adopted in TOPSIS modelling (cf. section 4.1) for the sake of comparability of results. The main idea is not only to assess whether the TOPSIS method increases the discriminatory power of the analysis, but also whether their scores are less symmetrical around the mean when compared to the traditional models in order to increase contrasts for the subsequent neural network analysis.

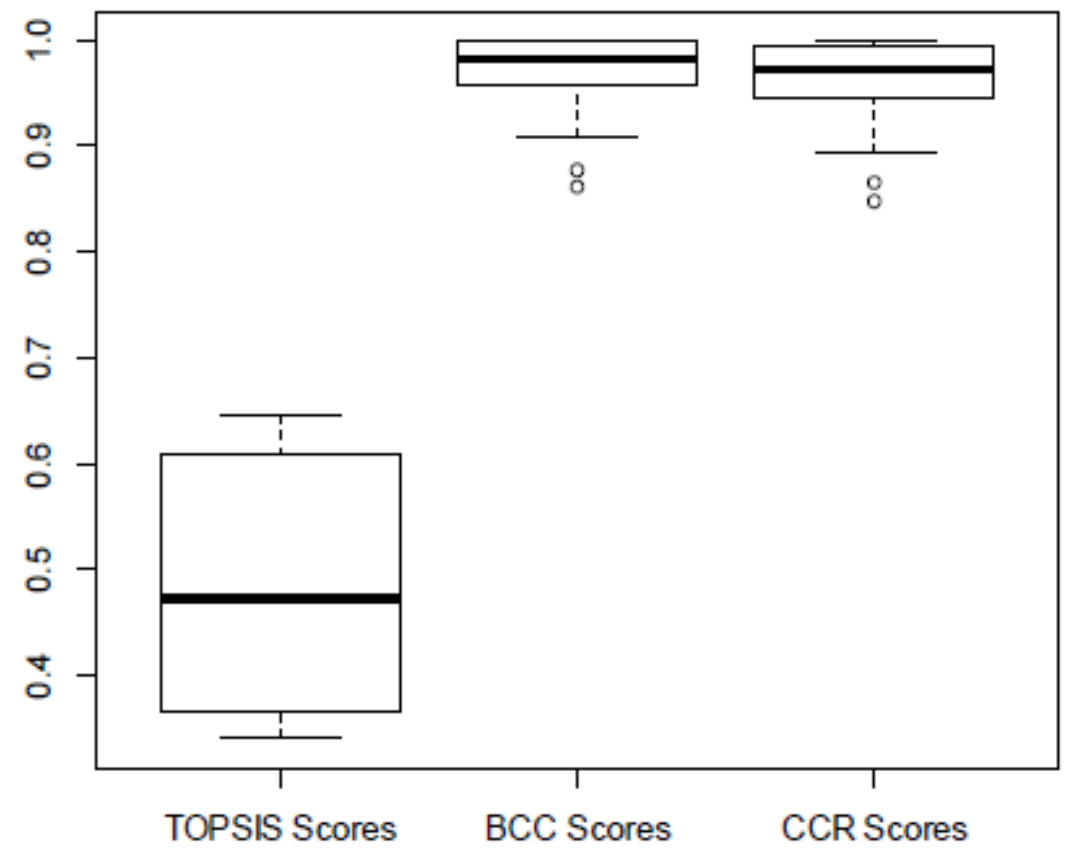

Fig. 4 Robustness analysis

The mean overall performance scores in the TOPSIS method is 0.49 , whereas the traditional BCC and CCR models presented mean values of 0.97 and 0.96, respectively. These results suggest that the discriminatory power of the TOPSIS method is higher than 
those observed in traditional models because their scores are lower. The impact of TOPSIS performance modeling can also be found in other statistical properties derived from the frequency distribution of the performance estimates in both models. Skewness is close to zero (0.158 against -1.475 [BCC] and -1.294 [CCR]), suggesting that, in the TOPSIS method, performance scores are more symmetrical around the mean, thus favoring the neural network analysis. Nevertheless, Spearman rank correlations between performance scores derived from traditional DEA models and the TOPSIS method were found to be significant at 0.01 (0.23 and 0.28 in the CCR and BCC cases, respectively), thus suggesting isotonic results for both models when the yearly performance ranks for energy performance in South Africa are placed into perspective for these three models.

Now, as regards to the contextual variables and test of global separability (Daraio et al., 2010), the empirical value of the test statistic for the TOPSIS scores was not only found to be close to zero (0.0512), but also to be inferior than the test values on the BCC $(0.146)$ and the CCR frontiers (0.092). As expected, this test value goes far from zero in cases where estimates are biased towards one (cf. Fig. 4). Global separability, therefore, appears to be consistent with the use of TOPSIS on the sample data to the detriment of DEA models. This suggests that the contextual variables considered here affect only the distribution of performance scores and not the attainable input/output combinations (or the shape of the underlying production set).

In addition, the weighted linear optimization model proposed by $\mathrm{Ng}$ (2007) and inspired in Pearman (1977) is used to generate various sets of weights for the inputs and the output before conducting the robustness analysis on TOPSIS performance scores with respect to the weighting criteria. Under Ng's approach, the weights are endogenous, that is, they are automatically generated when the model is optimized and, therefore, they are not subjective. Besides, Ng's approach can be used in a supplementary fashion with several MCDM techniques, such as TOPSIS, in which weights can be specified exogenously by decisionmakers, thus involving some degree of subjectivity.

However, as long as in the model presented in $\mathrm{Ng}$ (2007) the decision maker has to rank the importance of criteria before solving the model, we used combinatorial analysis to generate - within the ambit of the R statistical package - the full universe of combinations 
where the four inputs and the single output are ranked in different orders of importance. More precisely, the model presented in $\mathrm{Ng}$ (2007) was run 5! = 120 times for the full set of inputs/output combinations in different orders of importance. In all times, the summation of the weights for the inputs and the output was equal to one, observing the constraints of the linear program. Readers should refer Section 3.4 for a full description of the model features and its specificities. Then, as a final step, this full set of inputs-output weight combination was used to re-compute the TOPSIS performance scores.

Table 2 depicts the results for the mean TOPSIS criteria weights with respect to different groups of results in terms of the Spearman's rank correlations and their respective significances between the original TOPSIS scores with equal weights and each one of the 120 input-output weight combinations. Four groups were defined. In the first group, the correlations are found to be positive and significant at 0.05 . This group is not only the most numerous by far with $91.67 \%$ of the total 120 cases, but also within this group it is possible to affirm that this set of weights is robustly represented by the original TOPSIS scores with equal weights. Isotonicity thus holds when performance scores are compared. On the other hand, in the second group, although correlations are still positive, they are not significant. No case was verified, however. The third and the fourth groups with negative correlation presented fewer cases, less than $9 \%$ in total, but with no isotonicity with the original performance scores computed for equal weights. This corroborates the robustness of the sensitivity analysis performed, since a few negative correlations were found, irrespectively of their significance level. These few cases are counterintuitive ones, since labor and capital account only for a quarter of total weight, while value creation (GDP), energy consumption, and $\mathrm{CO} 2$ emissions account for around three-quarters of it, as such a huge production output could have come from a tiny physical and human resource base.

Readers should observe that, considering only the positive and significant cases, as regards the inputs/single output criteria, higher weights on $\mathrm{CO} 2$ emissions and capital stock to the detriment of labor force and GDP make the original TOPSIS scores with equal weights more representative, while energy consumption stands in between with an intermediate weight. This suggests a trade-off, mediated by the energy consumption level, between a dirty industrial economy that is high-performer and a cleaner one with low value added that is low- 
performer. Low value added can be inferred or proxied by the smallest weight attributed to GDP.

Table 2: Mean TOPSIS criteria weights per group of result

\begin{tabular}{|c|c|c|c|c|c|}
\hline \multirow{2}{*}{\multicolumn{2}{|c|}{ TOPSIS Criteria }} & \multicolumn{2}{|c|}{ Positive Correlation } & \multicolumn{2}{|c|}{ Negative Correlation } \\
\hline & & \multirow{2}{*}{\begin{tabular}{|r|} 
Significant \\
0.216 \\
\end{tabular}} & \multirow{2}{*}{\begin{tabular}{|r|}
$\begin{array}{l}\text { Not } \\
\text { Significant }\end{array}$ \\
0.000 \\
\end{tabular}} & \multirow{2}{*}{\begin{tabular}{|r} 
Significant \\
0.040 \\
\end{tabular}} & \multirow{2}{*}{\begin{tabular}{|r|}
$\begin{array}{l}\text { Not } \\
\text { Significant }\end{array}$ \\
0.054 \\
\end{tabular}} \\
\hline \multirow{4}{*}{ Inputs } & Labor Force & & & & \\
\hline & Capital Stock & 0.228 & 0.000 & 0.177 & 0.205 \\
\hline & \begin{tabular}{|l|}
$\mathrm{CO} 2$ \\
Emissions
\end{tabular} & 0.250 & 0.000 & 0.257 & 0.179 \\
\hline & \begin{tabular}{|l|} 
Energy \\
Consumption
\end{tabular} & 0.220 & 0.000 & 0.130 & 0.191 \\
\hline Output & GDP & 0.084 & 0.000 & 0.397 & 0.371 \\
\hline \multicolumn{2}{|c|}{ Number of cases } & 110 & 0 & 1 & 9 \\
\hline \multicolumn{2}{|c|}{$\%$ of cases } & $91.67 \%$ & $0 \%$ & $0.83 \%$ & $7.50 \%$ \\
\hline
\end{tabular}

Furthermore, another robustness analysis was also performed before running the neural network analysis. This time with respect to the impact of contextual variables on performance scores. More precisely, TOPSIS scores were regressed against the set of contextual variables presented in Table 1 using Tobit regression (see Moyo, 2012, for instance, for further details on Tobit regression). The results presented in Table 3 corroborate previous analysis derived from Fig. 2 and show a significant impact of the dummy variables of oil shock, China's emergence, and Apartheid regime on the performance levels. Readers should note, however, that the emergence of China (1995-2014) was modeled as a complement of the Apartheid regime (1965-1994), which has been discarded by the model due to collinearity.

The linear and squared trend components also showed significant results, corroborating with the overall picture described in Fig. 1 of decreasing energy performance over the course of 50 years. Besides these results, it is worth noting that although the KL ratio showed no significant effect over performance levels-different from the positive impact that was expected and found for the manufacturing employment index-the 
$\mathrm{CO}_{2}$ /Energy ratio presented a negative impact, thus suggesting, as expected, that energy performance decreases either as a consequence of pollutant economic activities (higher $\mathrm{CO}_{2}$ emissions) or as a result of energy intensive economic activities. One possible explanation for this phenomenon encompassing both high $\mathrm{CO}_{2}$ emissions and energy intensive activity in the context of an economy that is increasingly low value-added and service-driven - as indicated in Fig 3-is road transportation, the most pollutant and energy inefficient of all transportation modes. As a matter of fact, in South Africa, road transportation for cargoes accounts for $87.9 \%$ in terms of tonnage and $69.5 \%$ in terms of tonnage per kilometers, with railway accounting for the remainder $\left(10^{\text {th }}\right.$ Annual State of Logistics Survey for South Africa 2013). This amount is much higher than that seen in the US, for instance, where road transportation accounts for about $15 \%$ of cargo transportation in all transport modes.

Table 3: Tobit regression results

\begin{tabular}{lcccl}
\hline Coefficients & Estimate & Std. Error & z value & \multicolumn{1}{c}{$\operatorname{Pr}(>|\mathrm{z}|)$} \\
\hline (Intercept) & $1.415 \mathrm{e}+00$ & $3.503 \mathrm{e}-01$ & 4.038 & $5.40 \mathrm{e}-05 * * *$ \\
KL Ratio & $-2.870 \mathrm{e}-02$ & $5.526 \mathrm{e}-02$ & -0.519 & 0.6034 \\
$\mathrm{CO}_{2}$ /Energy Ratio & $-2.323 \mathrm{e}-01$ & $9.236 \mathrm{e}-02$ & -2.516 & $0.0119 *$ \\
Employment Index & $1.915 \mathrm{e}-03$ & $4.872 \mathrm{e}-04$ & 3.930 & $8.50 \mathrm{e}-05 * * *$ \\
China Emergence & $-2.760 \mathrm{e}-02$ & $1.137 \mathrm{e}-02$ & 2.427 & $0.0152 *$ \\
Oil Shock & $1.950 \mathrm{e}-02$ & $7.937 \mathrm{e}-03$ & 2.456 & $0.0140 *$ \\
Trend & $-1.795 \mathrm{e}-02$ & $1.843 \mathrm{e}-03$ & -9.741 & $<2 \mathrm{e}-16 * * *$ \\
Trend.2 & $1.975 \mathrm{e}-04$ & $3.098 \mathrm{e}-05$ & 6.376 & $1.82 \mathrm{e}-10 * * *$ \\
Log(scale) & $-4.289 \mathrm{e}+00$ & $1.000 \mathrm{e}-01$ & -42.886 & $<2 \mathrm{e}-16 * * *$
\end{tabular}

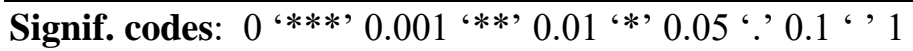

Log-likelihood: 143.5 on 9 Df

Wald-statistic: 3239 on 7 Df, p-value: <2.22e-16

Pseudo-R square: 0.9847979

Next, a neural network analysis was conducted on the TOPSIS performance scores using the contextual variables presented in section 4 as their predictors. All steps taken followed those presented in Faraway (2006) and in Kuhn and Johnson (2013). When different 
cross-validation measures are applied and different numbers of hidden layers are considered, a clear picture emerges with respect to the response bias or the over-fitting within each predictive technique. Fig. 5 illustrates the apparent Root Mean Squared Error (RMSE), which tends to decrease with the number of hidden layers of the neural network. This result clearly suggests a positive response bias towards a larger number of hidden layers (errors decay with a larger number of hidden layers).

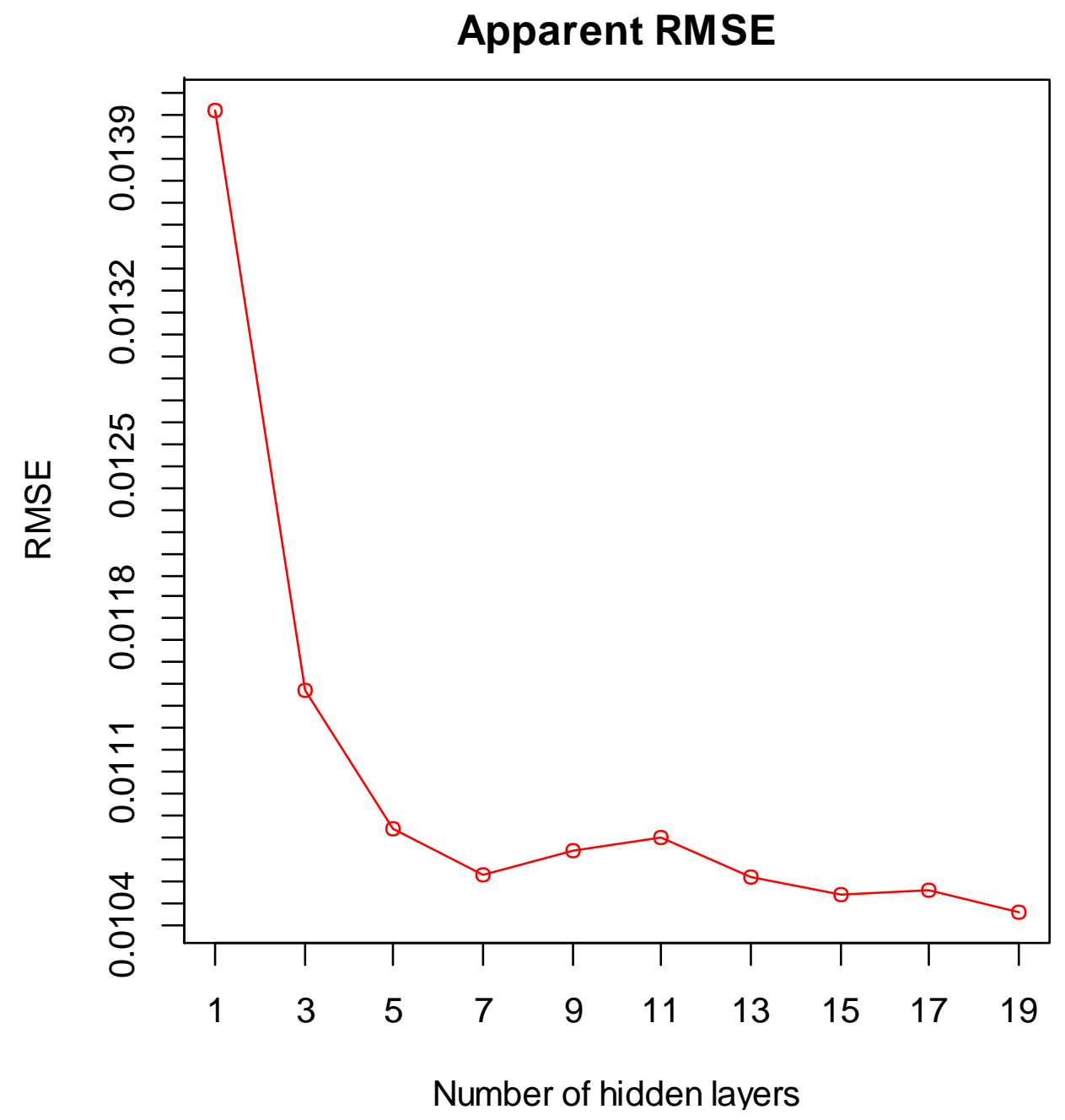

Fig 5. Apparent RMSE.

Additionally, Fig. 6 illustrates that a common pattern within the cross-validation methods is seen where RMSE is smaller for higher hidden layer values and peaks at lower values in the context of this particular neural network. The most accurate neural network obtained $(\mathrm{RMSE}=0.00825)$ used the 10-fold cross-validation technique for 15 hidden layers 
and a decay rate of 0.0168 . This represents a mean error rate of 0.82 percent points if we consider the performance scale ranging from 0 to $100 \%$ and a pseudo $\mathrm{R}$ square of 0.999 .
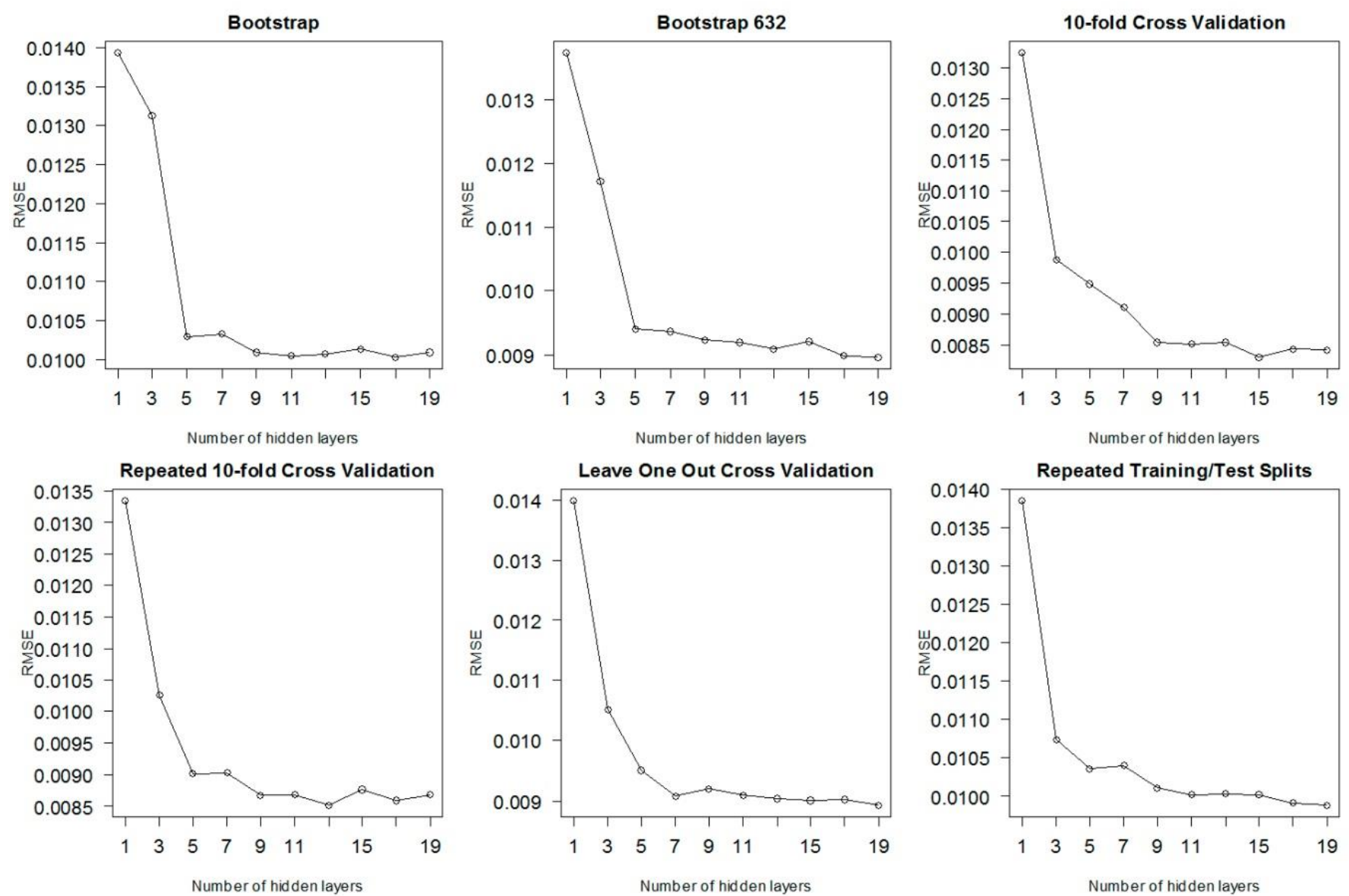

Fig 6. Cross-validated performance profiles over different values of the tuning parameter.

The relative importance of each contextual variable is given in Fig. 7. As regards to TOPSIS performance scores, the top predictors for the neural networks of South African energy performance are variables related to the industrial (manufacturing employment index) and to the pollutant $\left(\mathrm{CO}_{2}\right.$ /Energy ratio) activities besides the overall declining trend, which can be also described by the Apartheid regime, the Chinese rise as a superpower, and the KL ratio. The remainder variable, oil shock, presented a negligible impact on energy performance in South Africa in an isolated way. 


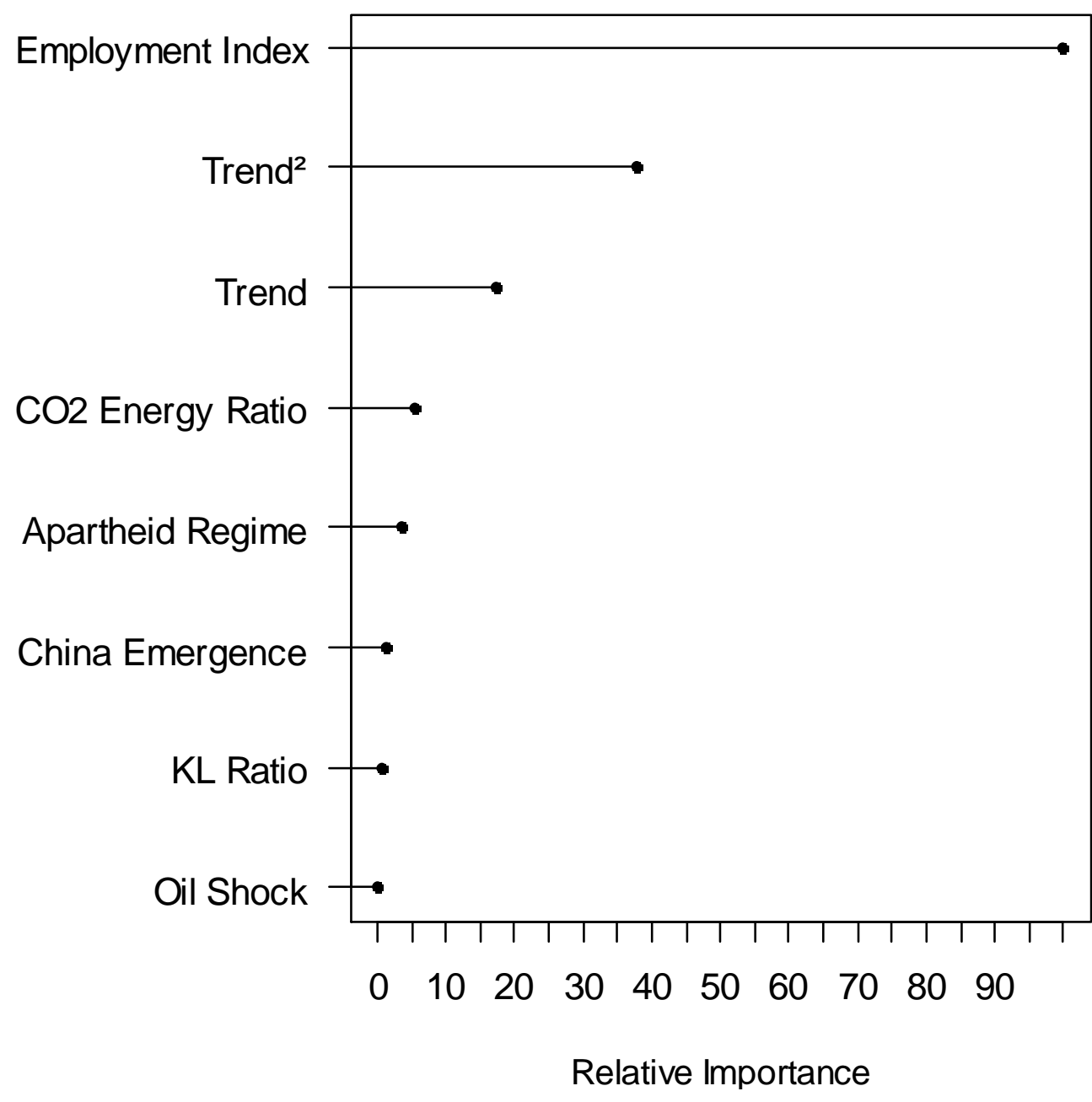

Fig 7. Relative importance of contextual variables.

Figure 8 presents the sensitivity analysis on the TOPSIS performance estimates for the best neural network model. Results confirmed the signs found in the Tobit regression results despite their significance levels and relative importance, as measured by the regression coefficients, unveiling non-linear relationships between these variables. They corroborate the transition of the South African economy to a low-value added, service-based one. Although the ratio of the $\mathrm{CO}_{2}$ emissions over the course of the years are diminishing against the overall energy consumption, the ratio of the productive capital stock, capable of leveraging and sustaining accelerated GDP growth, is also diminishing when compared to the workforce amount. The decrease in energy performance scores therefore is mostly explained in the output side by the deceleration in GDP growth and, in the input side, by 
changes in the overall productive structure of the South African economy towards low value added services, intensive in energy consumption and $\mathrm{CO}_{2}$ emissions.

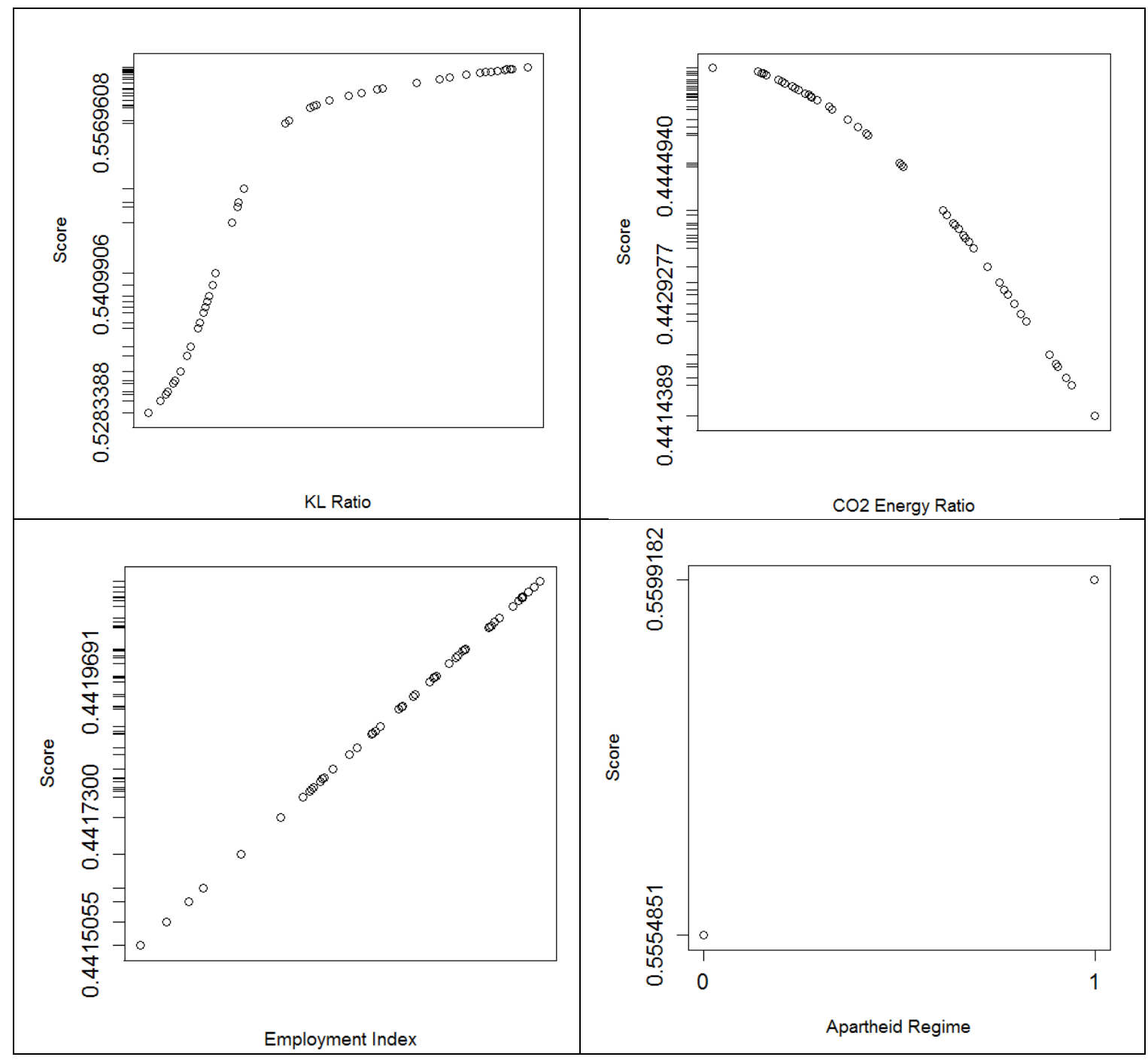




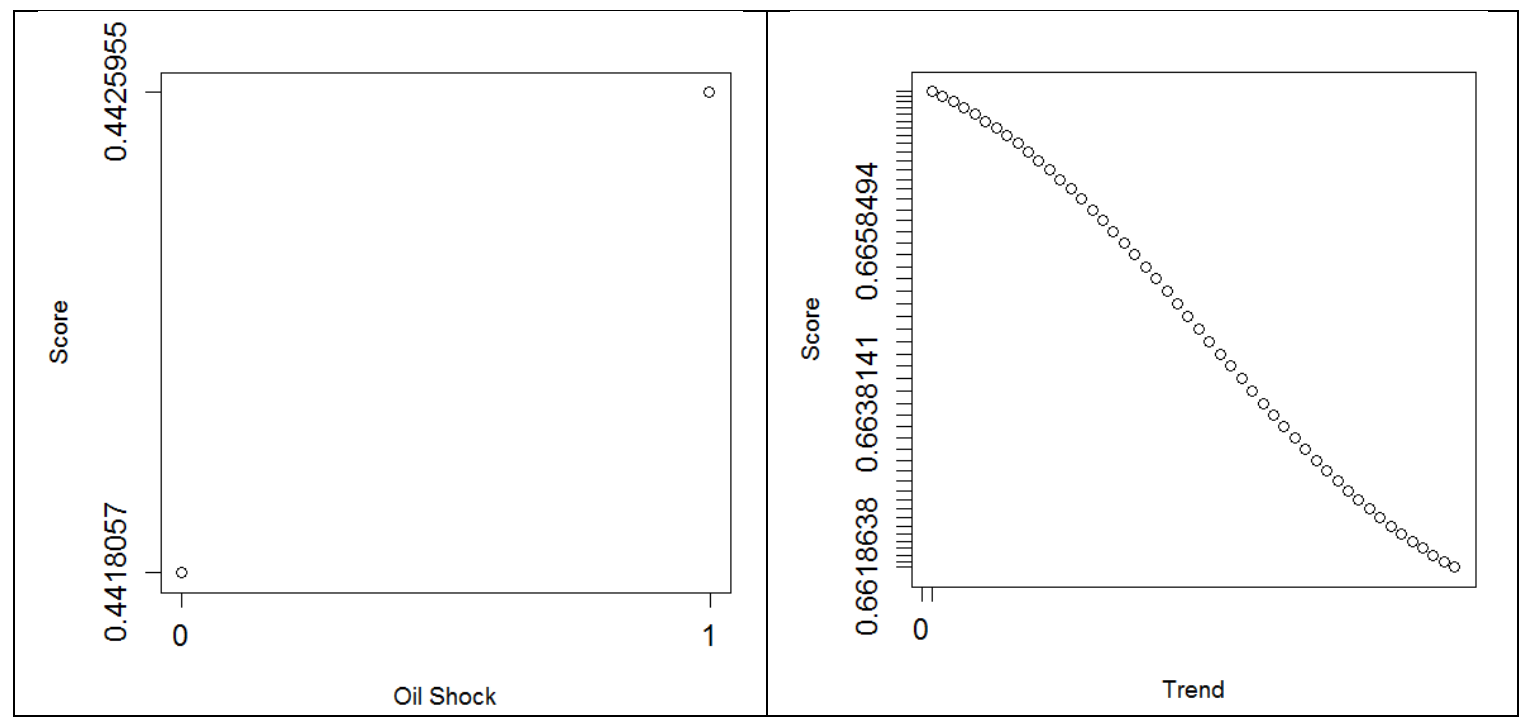

Fig 8. Neural network sensitivity analysis for the performance scores.

\section{Conclusion}

This paper presents an analysis of the energy performance in South Africa using TOPSIS and neural networks. While TOPSIS enables the assessment of the evolution of this performance over the course of the years, neural networks help in explaining several determinants of performance. South Africa's energy performance score has declined systematically over the years. The major factor relates to the structural changes undergone by the South African economy over the last 50 years. Specifically, the decrease in energy performance is mainly explained by the manufacturing employment index and changes in the overall productive structure of the South African economy towards low value added services, which are intensive in energy consumption and $\mathrm{CO}_{2}$ emissions. These findings have important policy implications. Economic and industrial policies need to be integrated to ensure a balance between energy performance and economic growth. This is because improved energy performance is associated with a number of benefits: energy security, environmental quality, development, consumer welfare, among other benefits that eventually promote growth. Although South Africa's government is already helping to stimulate investment into energy improvement via its national energy efficiency strategy, there is the need to monitor, enforce, and evaluate such strategies on a continuous basis as these are key 
to identifying gaps and reaching the targets set both at the aggregate and sectoral levels. Competitive energy markets, coupled with the appropriate regulations, need to be put in place. The government may for instance, consider revising the electricity tax incentive upwards in the coming years to motivate the businesses to invest in energy efficiency in particular and general performance of the energy sector. Collaborating with the private financial institutions to facilitate energy improvement financing and the market could also be beneficial. Further, there is a need to continuously integrate and coordinate new and emerging technologies that enhance energy performance. A move away from fossil fuelbased energy to a greener and renewable energy sources may be helpful. Barriers to the large scale spread of energy efficient technologies, which are often related to governance, institutions and information, among other actions, rather than economic justifications, can be overcome with carefully designed regulations policies, strategies, and enforcement mechanisms. The government can review regulations and subsidies in order to ensure that energy retail prices reflect the full costs of energy supply, delivery, and environmental costs. However, policies aimed at increasing the electricity level should be done in conjunction with policies that insulate the effect of such on low-income households. The need for a structural change towards sectors that consume less energy per unit of output and hence emit low $\mathrm{CO}_{2}$ cannot be overstressed. The government is already proposing to shift the economy to sectors such as trade and services. The benefits may not come so fast as other short term measures, but it will surely be sustainable in the long term.

\section{References}

Afshar, A., Mariño, M. A., Saadatpour, M. and Afshar, A. (2011). Fuzzy TOPSIS multicriteria decision analysis applied to karun reservoirs system. Water Resource Management, 25, 545-563.

Afsordegan, A., Sánchez, M., Agell, N., Zahedi, S. and Cremades, L. V. (2016) International Journal of Environmental Science and Technology,13 (6),1419-1432.

Apergis, N., Aye, G.C., Barros, C.P., Gupta, R., Wanke, P., 2015, Energy efficiency of selected OECD countries: A slacks based model with undesirable outputs, Energy Economics, Volume 51, Pages 45-53.

Azadeh, A., Sheikhalishahi, M., Boostani, A. 2014 A Flexible Neuro-Fuzzy Approach for Improvement of Seasonal Housing Price Estimation in Uncertain and Non-Linear Environments, South African Journal of Economics, 82 (4): 567- 582. 
Bădin, L., Daraio, C., Simar, L., 2012. How to measure the impact of environmental factors in a nonparametric production model, European Journal of Operational Research, 223(3): 818-833.

Banker, R.D., Charnes, A., \& Cooper, W.W. 1984. Some models for estimating technical and scale inefficiencies in data envelopment analysis. Management Science, 30(9), 1078-1092.

Barros, C. P., \& Wanke, P. (2015). An analysis of African airlines efficiency with two-stage TOPSIS and neural networks. Journal of Air Transport Management, 44-45, 90-102. doi:http://dx.doi.org/10.1016/i.jairtraman.2015.03.002

Behzadian, M., Otaghsara, S.K., Yazdani, M., and Ignatius, J. (2012) A state-of the-art survey of TOPSIS applications. Expert Systems with Applications 39, 13051-13069.

Beygelzimer, A., Kakadet, S., Langford, J. 2015, Package FNN. Accessed at http://cran.rproject.org/web/packages/FNN/FNN.pdf.

Behzadian, M., Khanmohammadi Otaghsara, S., Yazdani, M., Ignatius, J., 2012. A state-of the-art survey of TOPSIS applications. Expert Systems with Applications 39, 1305113069. doi:http://dx.doi.org/10.1016/j.eswa.2012.05.056

Bilbao-Terol, A., Arenas- Parra, M., Cañal Fernandes, V., 2014. Using Topsis for assessing the sustainability of government bond funds. Omega, 49, 1-17. DOI: 10.1016/j.omega.2014.04.005

Bishop, CM, 1995, Neural Networks for Pattern Recognition, Oxford University Press.

Boran, F. E., Genç, S., Kurt, M. and Akay, D. (2011). Personnel selection based on intuitionistic fuzzy sets. Human Factors and Ergonomics in Manufacturing \& Service Industries, 1-11.

Brans, J.P., Vincke, P.H., 1985. A preference ranking organization method: The Promethee method. Manag. Sci. 31, 647-56.

Bulgurcu, B.K. (2012) Application of TOPSIS Technique for Financial Performance Evaluation of Technology Firms in Istanbul Stock Exchange Market. Procedia Social and Behavioral Sciences, 62(24), 1033-1040.

Charnes, A., Cooper, W.W., Rhodes, E., 1978. Measuring efficiency of decision making units. Eur. J. Oper. Res. 2(6), 429-444.

Chen M-C (2007). Ranking discovered rules from data mining with multiple criteria by data envelopment analysis. Expert Systems with Applications 33(4): 1110-1116.

Chen T-Y (2002). A comparison of chance-constrained DEA and stochastic frontier analysis: bank efficiency in Taiwan. Journal of the Operational Research Society 53(5): 492-500.

Chen Y-S and Cheng C-H (2013). Hybrid models based on rough set classifiers for setting credit rating decision rules in the global banking industry. Knowledge-Based Systems 39: 224-239.

Chen, F-H., Chi, D-J., Wang, Y-C., 2015, Detecting biotechnology industry's earnings management using Bayesian network, principal component analysis, back propagation neural network, and decision tree. Econ. Model. 46, 1-10. 
Chen, S., Leng, Y., Mao, B., Liu, S., 2014, Integrated weight-based multi-criteria evaluation on transfer in large transport terminals: A case study of the Beijing South Railway Station, Transportation Research Part A: Policy and Practice, Volume 66, Pages 1326

Chen, C. T., Lin, C. T., and Huang, S. F. (2006). A fuzzy approach for supplier evaluation and selection in supply chain management. International Journal of Production Economics, 102, 289-301.

Claveria, O., Torra, S., 2014. Forecasting tourism demand to Catalonia: Neural networks vs. time series models. Econ. Model. 36, 220-228.

Corrente, S., Greco, S., Slowinski, R., 2013. Multiple criteria hierarchy process with electre and promethee. Omega, 41(5), 820-840. DOI: 10.1016/j.omega.2012.10.009.

Daraio, C. et al. (2010). Testing Whether Two-Stage Estimation is Meaningful in Nonparametric Models of Production. Discussion Paper \#1031, Institut de Statistique, UCL, Belgium.

Department of Energy (DOE), 2014. 12L Regulations in relation to the national energy efficiency strategy.

Ertugrul I and Karakasoglu N (2009). Performance evaluation of Turkish cement firms with fuzzy analytic hierarchy process and TOPSIS methods. Expert Systems with Applications 36(1): 702-715.

Faraway, J.J., 2006. Extending the linear model with R: Generalized lienar, mixed effects and nonparametric regression models. Chapman \& Hall/CRC, Boca Raton.

Feng, C-M., Wang, R-T., 2001, Considering the financial ratios on the performance evaluation of highway bus industry, Transport Reviews, 21 (4), pp. 449-467

Feng, L., Zhang, J., 2014. Application of artificial neural networks in tendency forecasting of economic growth. Econ. Model. 40, 76-80.

Geisser S (1993). Predictive Inference: An introduction. Chapman \& Hall: New York.

Gomez-Lopez, M. D., Bayo, J., Garcia-Cascales, M. S. and Angosto, J. M. (2009). Decision support in disinfection technologies for treated wastewater reuse. Journal of Cleaner Production, 17, 1504-1511.

Gouws, P.A.,. Brent, A.C., Pierce, W.T., 2012. The contribution of energy efficiency towards the success of industrial organisations in South Africa. South African Journal of Industrial Engineering, 23 (2): 57-65.

Hassan, M., Hawas, Y., Ahmed, K., 2013, A multi-dimensional framework for evaluating the transit service performance, Transportation Research Part A: Policy and Practice, Volume 50, Pages 47-61.

Hatami-Marbini, A., Tavana, M., 2011. An extension of the Electre 1 method for group decision making under a fuzzy environment. Omega, 39(6), 373-386. DOI: 10.1016/j.omega.2010.12.005.

Hayfield, T., Racine, J. (2008). Nonparametric econometrics: The np package. Journal of Statistical Software, 27, pp. 1-32. 
Hemmati M, Dalghandi S A and Nazari H (2013). Measuring relative performance of banking industry using a DEA and TOPSIS. Measurement Science Letters 3(2): 499503.

Hwang C L and Yoon K (1981). Multiple attribute decision making: methods and applications, A state of the art survey. Springer-Verlag: New York.

Hwang, C.-L., \& Yoon, K. (2012). Multiple attribute decision making: methods and applications a state-of-the-art survey (Vol. 186): Springer Science \& Business Media.

Inglesi-Lotz, R., Pouris, A.,2012. Energy efficiency in South Africa: A decomposition exercise. Energy, 42, 113-120.

Inglesi-Lotz R., Blignaut J., 2011. Estimating the Price Elasticity of Demand for Electricity by Sector in South Africa. South African Journal of Economic and Management Science, 14(4), 449-465.

International Emissions Trading Association, IETA, 2014. South Africa: The world's carbon markets: a case study guide to emissions trading. http://www.ieta.org/assets/EDFCaseStudyMarch2014/south\%20africa\%20case $\% 20$ study\%20march\%202014.pdf.

IEA. 2012. Energy balances for non-OECD countries.

IEA, 2013a. World Energy Outlook, 2013. http://www.worldenergyoutlook.org/.

IEA, 2013b. Energy efficiency market report 2013. Market trends and medium-term prospects. http://www.iea.org/publications/freepublications/publication/energy-efficiencymarket-report-2013.html

IEA, 2014a. CO2 emissions from fuel combustion IEA Statistics. IEA Highlights (2014 Edition)

IEA, 2015. Energy efficiency in emerging economies (E4) programme. http://www.iea.org/topics/energyefficiency/e4/

Jahanshahloo, G.R, Lotfi, F.H., Davoodi, A.R., 2009, Extension of TOPSIS for decisionmaking problems with interval data: Interval efficiency, Mathematical and Computer Modelling, Volume 49, Issues 5-6, Pages 1137-1142.

Jefmański, B., \& Dudek, A. (2015). The fuzzy TOPSIS method and its implementation in the R programme. Informatyka Ekonomiczna(1 (35)), 19-27.

James G, Witten D, Hastie T and Tibshirani R (2013). An introduction to statistical learning with applications in $R$. Springer: New York.

Kaya, T. and Kahraman, C. (2011). Multi criteria decision making in energy planning using a modified fuzzy TOPSIS methodology. Expert Systems with Applications, 38, $6577-6585$.

Kahraman, C., Engin, O., Kabak, O., \& Kaya, I. (2009). Information systems outsourcing decisions using a group decision-making approach. Engineering Applications of Artificial Intelligence, 22, 832-841. 
Kelemenis, A., Ergazakis, K., \& Askounis, D. (2011). Support managers' selection using an extension of fuzzy TOPSIS. Expert Systems with Applications, 38, 2774-2782.

Kohler, M., 2013. Differential electricity pricing and energy efficiency in South Africa. Economic Research Southern Africa (ERSA) working paper 396 December 2013.

Kourtesi, S., Fousekis, P., and Polymeros, A. (2012). "Conditional Efficiency Estimation With Environmental Variables: Evidence From Greek Cereal Farms, Scientific Bulletin - Economic Sciences, University of Pitesti, 11(1): 43-52.

Kuhn M and Johnson K (2013). Applied predictive modeling. Springer: New York.

Lai Y J, Liu T Y and Hwang, C L (1994). Topsis for MCDM. European Journal of Operational Research 76(3): 486-500.

Ledolter J (2013). Data mining and business analytics with R. Wiley: New Jersey.

Madeira Junior, A.G., Cardoso Junior, M., Carmen, M., Belderrain, N., Correia, A.R., Schwanz, S.H., 2012, Multicriteria and multivariate analysis for port performance evaluation, International Journal of Production Economics, Volume 140, Issue 1, Pages 450-456

Mandal, S.K., Madheswaran, S. 2009. Measuring Energy Use Efficiency in Presence of Undesirable Output: An Application of Data Envelopment Analysis (DEA) to Indian Cement Industry. Working paper 235, The Institute for Social and Economic Change, Bangalore.

Mihaiu, D.M., Opreana, A. and Cristescu, M.P. (2010) Efficiency, Effectiveness and Performance of the Public Sector. Romanian Journal of Economic Forecasting, 4, 132-147.

Moyo, B. (2012) Infrastructure quality and manufacturing exports in Africa: a firm-level analysis. South African Journal of Economics, 80 (3): 367-386.

Munda, G. and Nardo, M. (2003) On the methodological foundations of composite indicators used for ranking countries, OECD/JRC Workshop on composite indicators of country performance, Ispra, Italy, May 12.

Ng,W.L. (2007).A simple classifier for multiple criteria ABC analysis. Eur. J. Oper. Res. 177 (1), 344-353.

OECD 2011. OECD Green Growth Strategies: Energy. OECD Publishing.

Olson, D.L. (2004) Comparison of Weights in TOPSIS Models. Mathematical and Computer Modelling, 40 (7-8), 721-727.

Opricovic S (1998). Multicriteria optimization of civil engineering systems. Faculty of Civil Engineering: Belgrade.

Opricovic S and Tzeng G H (2007). Extended Vikor method in comparison with out-ranking methods. European Journal of Operational Research 178(2): 514-529.

Osei-Bryson K-M and Ngwenyama O (2014). Advances in research methods for information systems research: Data mining, data envelopment analysis, value focused thinking. Springer: New York. 
Pearman, A.D., 1977. A weighted maximin and maximax approach to multiple criteria decision making. Operational Research Quarterly 28 (3), 584-587.

Pirdavani, A., Brijs, T., Geert, W., 2010, A Multiple Criteria Decision-Making Approach for Prioritizing Accident Hotspots in the Absence of Crash Data, Transport Reviews, Vol. 30, Iss. 1, 2010.

Ramanathan U (2013). Aligning supply chain collaboration using analytical hierarchy Process. Omega 41(2): 431-440.

Rao, P. V., \& Baral, S. S. (2011). Attribute based specification, comparison and selection of feed stock for anaerobic digestion using MADM approach. Journal of Hazardous Materials, 186, 2009-2016.

Ripley B (1995). Statistical ideas for selecting network architectures. In: Kappen B and Gielen S (eds). Neural Networks: Artificial Intelligence and Industrial Applications: Proceedings of the Third Annual SNN Symposium on Neural Networks, Nijmegen, The Netherlands, 14-15 September 1995. Springer: London, pp 183-190.

Saaty, T.L., 1980. The analytical hierarchy process, MacGraw Hill, New York.

Seçme N Y, Bayrakdaroglu A and Kahraman G (2009). Fuzzy performance evaluation in Turkish banking sector using Analytic Hierarchy Process and TOPSIS. Expert Systems with Applications 36(9): 11699-11709.

Shaverdi M, Akbari M and Tafti S F (2011), Combining fuzzy MCDM with BSC approach in performance evaluation of Iranian private banking sector. Advances in Fuzzy Systems, Volume 2011, pp. 1-11.

Simar, L., Wilson, P., 2011, Two-stage DEA: caveat emptor , Journal of Productivity Analysis, V 36, N 2, 205-218.

Siskos, E., Askounis, D., Psarras, J., 2014. Multicriteria decision support for global egoverning evaluation. Omega, 46, 51-63. DOI: 10.1016/j.omega.2014.02.001

Song, M-L., Zhang, L-L., Liu, W., Fisher, R. 2013. Bootstrap-DEA analysis of BRICS' energy efficiency based on small sample data. Applied Energy, 112, 1049-1055.

State of Logistics Survey, South Africa (2013).

Statistics South Africa, 2015.

Tavana, M., Zandi, F., Katehakis, M.N., 2013, A hybrid fuzzy group ANP-TOPSIS framework for assessment of e-government readiness from a CiRM perspective, Information \& Management, Volume 50, Issue 7, November 2013, Pages 383-397.

Titterington, M., 2010. Neural Networks. Wiley Interdiscip. Rev.: Comput. Stat. 2 (1), 1-8.

Torgo, L., 2011. Data Mining with R: Learning with Case Studies. CRC Press, Boca Raton.

Tsay, W.H., Chou, W.C., Hsu, W., 2009. The sustainability balanced scorecard as a framework for selecting social responsible investments: an effective MCDM model. J. Oper. Res. Soc. 60(10), 1396-410. Doi:10.1057/jors.2008.91.

Tsui, E., Garner, B.J., Staab, S., 2000. The role of artificial intelligence in knowledge management, Knowl.-Based Syst. 13 (5) 235-239. http://dx.doi.org/10.1016/S09507051(00)00093-9 
UNEP (United Nations Environment Programme) 2011. Decoupling and Sustainable Resource Management: Scoping the Challenges, UNEP, Paris.

Wang B, Nistor I, Murty T and Wei Y M, (2014). Efficiency assessment of hydroelectric power plants in Canada: A multi criteria decision approach. Energy Economics 46: 112-121.

Wanke, P., Azad, M. A. K., Barros, C. P., \& Hadi-Vencheh, A. (2015a). Predicting performance in ASEAN banks: an integrated fuzzy MCDM-neural network approach. Expert Systems, Article first published online: 18 DEC 2015. doi:http://dx.doi.org/10.1111/exsy.12144

Wanke, P., Pestana Barros, C., \& Chen, Z. (2015b). An analysis of Asian airlines efficiency with two-stage TOPSIS and MCMC generalized linear mixed models. International Journal of Production Economics, 169, 110-126. doi:http://dx.doi.org/10.1016/j.ijpe.2015.07.028

Wanke, P., Azad, M.D., Abul K., and Barros, C.P. (2016). Efficiency factors in OECD banks: A ten-year analysis. Expert Systems with Applications , 64, 208-227.

Wu, C-S, Lin,C-T, Lee, C., 2010, Optimal marketing strategy: A decision-making with ANP and TOPSIS, International Journal of Production Economics, Volume 127, Issue 1, September 2010, Pages 190-196.

Yan, G., Ling, Z., and Dequn, Z. (2011). Performance evaluation of coal enterprises energy conservation and reduction of pollutant emissions base on GRD-TOPSIS. Energy Procedia, 5, 535-539.

Zeydan, M. and Çolpan, C. (2009) A new decision support system for performance measurement using combined fuzzy TOPSIS/DEA approach. International Journal of Production Research, 47(15), 4327-4349.

Zhou, P., Ang, B.W., Poh, K.L., 2006, Comparing aggregating methods for constructing the composite environmental index: An objective measure, Ecological Economics, Volume 59, Issue 3, Pages 305-311.

Zhou, P., Ang, B.W., Zhou, D.Q., 2012, Measuring economy-wide energy efficiency performance: A parametric frontier approach, Applied Energy, Volume 90, Issue 1, Pages 196-200.

Zhou, P. \& Ang, B.W. (2009) Soc Indic Res 94: 83. doi:10.1007/s11205-008-9338-0 


\section{Appendix - Performance ranking}

\begin{tabular}{|r|r|r|}
\hline Ranking & \multicolumn{1}{l|}{$\begin{array}{l}\text { TOPSIS } \\
\text { Score }\end{array}$} & \multicolumn{1}{l|}{ Year } \\
\hline 1 & 0.6467 & 1967 \\
\hline 2 & 0.6465 & 1968 \\
\hline 3 & 0.6465 & 1969 \\
\hline 4 & 0.6456 & 1970 \\
\hline 5 & 0.6441 & 1966 \\
\hline 6 & 0.6427 & 1965 \\
\hline 7 & 0.6423 & 1971 \\
\hline 8 & 0.6386 & 1972 \\
\hline 9 & 0.6328 & 1973 \\
\hline 10 & 0.6310 & 1974 \\
\hline 11 & 0.6197 & 1975 \\
\hline 12 & 0.6117 & 1976 \\
\hline 13 & 0.6089 & 1978 \\
\hline 14 & 0.6062 & 1977 \\
\hline 15 & 0.6038 & 1979 \\
\hline 16 & 0.5940 & 1980 \\
\hline 17 & 0.5634 & 1981 \\
\hline 18 & 0.5380 & 1982 \\
\hline 19 & 0.5322 & 1983 \\
\hline 20 & 0.5131 & 1984 \\
\hline 21 & 0.5059 & 1985 \\
\hline 22 & 0.5018 & 1986 \\
\hline 23 & 0.4971 & 1987 \\
\hline 24 & 0.4818 & 1989 \\
\hline 25 & 0.4756 & 1991 \\
\hline 26 & 0.4717 & 1990 \\
\hline 27 & 0.4642 & 1988 \\
\hline 28 & 0.4611 & 1993 \\
\hline 29 & 0.4600 & 1992 \\
\hline & & \\
\hline 19 & & \\
\hline 13 & &
\end{tabular}

\begin{tabular}{|r|r|r|}
\hline Ranking & $\begin{array}{l}\text { TOPSIS } \\
\text { Score }\end{array}$ & \multicolumn{1}{l|}{ Year } \\
\hline 30 & 0.4514 & 1994 \\
\hline 31 & 0.4378 & 1995 \\
\hline 32 & 0.4128 & 1996 \\
\hline 33 & 0.4115 & 1998 \\
\hline 34 & 0.4094 & 1997 \\
\hline 35 & 0.3861 & 2002 \\
\hline 36 & 0.3838 & 1999 \\
\hline 37 & 0.3658 & 2007 \\
\hline 38 & 0.3657 & 2001 \\
\hline 39 & 0.3651 & 2003 \\
\hline 40 & 0.3631 & 2005 \\
\hline 41 & 0.3624 & 2006 \\
\hline 42 & 0.3617 & 2000 \\
\hline 43 & 0.3607 & 2013 \\
\hline 44 & 0.3600 & 2012 \\
\hline 45 & 0.3582 & 2014 \\
\hline 46 & 0.3523 & 2011 \\
\hline 47 & 0.3511 & 2008 \\
\hline 48 & 0.3482 & 2010 \\
\hline 49 & 0.3459 & 2004 \\
\hline 50 & 0.3404 & 2009 \\
\hline & & \\
\hline
\end{tabular}

